\title{
Modelling the L-Band Snow-Covered Surface Emission in a Winter Canadian Prairie Environment
}

\author{
Alexandre Roy ${ }^{1,2,3, *}$, Marion Leduc-Leballeur ${ }^{4}$, Ghislain Picard ${ }^{5}$, Alain Royer ${ }^{1,3}$ (D), \\ Peter Toose ${ }^{6}{ }^{\mathbb{D}}$, Chris Derksen ${ }^{6}$, Juha Lemmetyinen ${ }^{7}$, Aaron Berg ${ }^{8} \mathbb{D}$, Tracy Rowlandson 8 \\ and Mike Schwank ${ }^{9,10}$ \\ 1 Université de Sherbrooke, 2500 boul. Université, Sherbrooke, QC J1K 2R1, Canada; \\ alain.royer@usherbrooke.ca \\ 2 Département des Sciences de l'Environnement, Université du Québec à Trois-Rivières, \\ 3351 Boulevard des Forges, Trois-Rivières, QC G9A 5H7, Canada \\ 3 Centre d'études Nordiques, Université Laval, Québec, QC G1V 0A6, Canada \\ 4 Institute of Applied Physics_Ational Research Council, 50019 Sesto Fiorentino, Italy; m.leduc@ifac.cnr.it \\ 5 Université Grenoble Alpes, CNRS, IGE, F-38000 Grenoble, France; Ghislain.picard@univ-grenoble-alpes.fr \\ 6 Climate Research Division, Environment and Climate Change Canada, Toronto, ON M3H 5T4, Canada; \\ peter.toose@canada.ca (P.T.); chris.derksen@canada.ca (C.D.) \\ 7 Finnish Meteorological Institute, FI-00101 Helsinki, Finland; Juha.Lemmetyinen@fmi.fi \\ 8 Department of Geography, Environment, and Geomatics University of Guelph, Guelph, ON N1G 2W1, \\ Canada; aberg@uoguelph.ca (A.B.); trowland@uoguelph.ca (T.R.) \\ 9 Gamma Remote Sensing AG, CH-3073 Gümligen, Switzerland; schwank@gamma-rs.ch \\ 10 Swiss Federal Research Institute WSL, CH-8903 Birmensdorf, Switzerland \\ * Correspondence: Alexandre.Roy@UQTR.ca; Tel.: +1-819-376-5011 (ext. 3680)
}

Received: 10 August 2018; Accepted: 5 September 2018; Published: 11 September 2018

\begin{abstract}
Detailed angular ground-based L-band brightness temperature $\left(T_{B}\right)$ measurements over snow covered frozen soil in a prairie environment were used to parameterize and evaluate an electromagnetic model, the Wave Approach for LOw-frequency MIcrowave emission in Snow (WALOMIS), for seasonal snow. WALOMIS, initially developed for Antarctic applications, was extended with a soil interface model. A Gaussian noise on snow layer thickness was implemented to account for natural variability and thus improve the $T_{\mathrm{B}}$ simulations compared to observations. The model performance was compared with two radiative transfer models, the Dense Media Radiative Transfer-Multi Layer incoherent model (DMRT-ML) and a version of the Microwave Emission Model for Layered Snowpacks (MEMLS) adapted specifically for use at L-band in the original one-layer configuration (LS-MEMLS-1L). Angular radiometer measurements $\left(30^{\circ}, 40^{\circ}, 50^{\circ}\right.$, and $\left.60^{\circ}\right)$ were acquired at six snow pits. The root-mean-square error (RMSE) between simulated and measured $T_{\mathrm{B}}$ at vertical and horizontal polarizations were similar for the three models, with overall RMSE between 7.2 and 10.5 K. However, WALOMIS and DMRT-ML were able to better reproduce the observed $T_{\mathrm{B}}$ at higher incidence angles $\left(50^{\circ}\right.$ and $\left.60^{\circ}\right)$ and at horizontal polarization. The similar results obtained between WALOMIS and DMRT-ML suggests that the interference phenomena are weak in the case of shallow seasonal snow despite the presence of visible layers with thicknesses smaller than the wavelength, and the radiative transfer model can thus be used to compute L-band brightness temperature.
\end{abstract}

Keywords: L-band emission; snow; WALOMIS; Frozen soil; ground-based radiometer 


\section{Introduction}

Three spaceborne L-band passive microwave radiometer missions were successfully launched in recent years for global monitoring of soil moisture and sea surface salinity. The European Space Agency (ESA) Soil Moisture and Ocean Salinity (SMOS) mission [1] was launched in November 2009 and continues to operate. The NASA Aquarius instrument on board the Aquarius/Satélite de Aplicaciones Científicas (SAC-D) mission, developed collaboratively between the U.S. National Aeronautics and Space Administration (NASA) and Argentina's space agency, Comisión Nacional de Actividades Espaciales (CONAE) acquired L-band observations between September 2012 and July 2015 [2], and the NASA Soil Moisture Active Passive (SMAP) satellite was launched in January 2015 [3]. These missions also provide useful information for cryosphere applications including monitoring the freeze/thaw (F/T) state of the land surface [4-7], estimating snow density and ground permittivity [8,9], and retrieving the thickness of thin sea ice [10].

Many studies have improved the modelling of L-band brightness temperature $\left(T_{\mathrm{B}}\right)$ for non-frozen surfaces [11], while numerous snow emission models exist for higher frequencies [12-15]. Comparatively few studies have calibrated and validated a snow emission model over frozen soil at L-band, as conventionally snow cover has been thought to have little relevance for L-band emissions because of inherent low scattering and absorption in dry snow. Recent studies, however, show the non-negligible impact of dry snow on L-band emission [16-18]. On the basis of the Microwave Emission Model for Layered Snowpacks (MEMLS, [12]) and the L-band microwave emission of the biosphere (L-MEB) model [11], Naderpour et al. [19] developed a simplified emission model specifically for L-band (called LS-MEMLS hereafter). The model neglects volume scattering in the snow layer, which is a plausible approximation for L-band. In cases of wet snow, absorption is considered by LS-MEMLS, whereas dry snow is assumed to be fully transparent, which is reasonable for seasonal snowpacks with thicknesses much smaller than L-band emission depth in dry snow (>300 m [20]). However, sensitivity to dry snow is retained though impedance matching and changes in the refraction angle at the snow-soil interface due to variable snow permittivity, which is in turn controlled by the dry snow density. The study also introduces a dual parameter retrieval approach for dry snow density and ground permittivity. The model and retrieval methods were evaluated with experimental data in boreal forest [9] and Canadian prairie environments [17]. However, the LS-MEMLS model approach does not take into account wave coherence effects [21], which potentially induces multiple reflections within a thin layer of snow or ice and associated interferences. Coherence effects may arise when the thickness of the layer is less than about a quarter of the wavelength ( $\lambda$; about $5 \mathrm{~cm}$ at L-band; [22]), and when layers are sufficiently homogeneous and parallel in the horizontal direction within the radiometer field of view. This can lead to significant variation in $T_{\mathrm{B}}$ especially at the horizontal polarization $[23,24]$.

In this study, we focus on modelling the snow contribution to L-band emission to better understand the effect of snow layering and interference for improved F/T monitoring and snow density retrieval. Three electromagnetic models were compared: the Dense Media Radiative Transfer-Multi Layer incoherent model (DMRT-ML) [14], the LS-MEMLS model [19], and the Wave Approach for LOw-frequency MIcrowave emission in Snow (WALOMIS) model $[18,25]$. The latter is a coherent model successfully used at L-band in the case of semi-infinite snow-firn over Antarctica. It was not previously applied to seasonal snow cover, so some improvements are introduced in this study.

Ground-based L-band radiometer measurements acquired in a Canadian prairie environment are used to first implement the WALOMIS model for seasonal snow, followed by comparisons with the LS-MEMLS and the DMRT-ML. In the following sections, we first present the ground-based radiometer observations and in situ measurements as well as the three snow microwave emission models and the soil emission model. The model parameterizations are presented, after which we present results and a comparison of the model performance. 


\section{Site and Data}

During the 2014-2015 winter, a ground-based L-band radiometer measurement campaign was conducted at the Kernen Crop Research Farm (KCRF; $52.149^{\circ} \mathrm{N} ; 106.545^{\circ} \mathrm{W}$ ), a 380 ha property within the city of Saskatoon owned and operated by the University of Saskatchewan, Canada. L-band radiometer measurements and coincident snow pit and meteorological observations were performed. The study area and the campaign and datasets are described in detail in Reference [17].

At KCRF, tree scenes were located adjacent to each other within the same field to ensure similarity in background emission, with only the overlying snow conditions altered. The three scenes include: Scene 1-Undisturbed snow: A scene of naturally accumulating snow-covered ground; Scene 2-Snow free: snow was removed on a weekly basis to maintain bare ground; Scene 3-Artificially compacted snow: a scene with deep and dense snow. Additional snow was manually added to Scene 3 and compacted on December 10th, 19th, 2014 and January 11th 2015 and then left to evolve naturally for the rest of the season. As this study focuses on snow emission modelling, Scene 2 was not used in this study. The scenes were characterized by silt-loam bare soil conditions. Wheat residue was noted and not disturbed during the study. Surface roughness was derived using a terrestrial Light Detection and Ranging (LiDAR) system using a surface roughness tool called Roughness from Point Cloud Profiles (RPCP) [26] implemented in Whitebox Geospatial Analysis Tools (GAT) software [27]. Surface roughness had a root-mean-square height (RMSH) of $1.78 \mathrm{~cm}$ and $1.64 \mathrm{~cm}$ within Scene 1 and 3 , respectively, at the beginning of the study and remained almost unchanged throughout the study (RMSH $=1.79 \mathrm{~cm}$ and $1.75 \mathrm{~cm}$ ).

L-band measurements were acquired by a surface-based hyperspectral dual polarization L-band Fourier transform radio-frequency interference (RFI) detecting radiometer with 385 channels designed for a frequency range from $1400 \mathrm{MHz}$ to $\approx 1550 \mathrm{MHz}$. The radiometer antenna is a 19-element air loaded conformal muffin tin design that has a $30^{\circ}$ half-power $(-3 \mathrm{~dB})$ beamwidth. A method was developed for separating out the thermal spectrum from RFI-contaminated channels to get unique RFI-free $T_{\mathrm{B}}$ from the measured spectrum [28]. Only the protected radio-astronomy frequency spectrum of $1400-1427 \mathrm{MHz}$ was used to calculate the $T_{\mathrm{B}}$. The radiometer was set $2.75 \mathrm{~m}$ above the surface, and measurements at the angles $30^{\circ}, 40^{\circ}, 50^{\circ}$, and $60^{\circ}$ relative to nadir were taken of the three scenes on a weekly basis. On 9 November 2014, radiometric measurements were taken while the soil was frozen and snow-free. From December 2014 to March 2015, six radiometric measurements were taken, coincident with manual snow pit measurements in the vicinity of Scene 1 and 3. The snow pits included documenting the snow stratigraphy, including the presence of ice lenses. Profiles of snow temperature and snow density were taken for the observed snow layers. Mass density was measured using a $100 \mathrm{~cm}^{3}$ density cutter, and samples were weighed with a digital scale with an accuracy of $\pm 0.1 \mathrm{~g}$. The snow and soil temperature at $2.5 \mathrm{~cm}$ intervals were measured with a digital temperature probe $\left( \pm 0.1^{\circ} \mathrm{C}\right)$. Soil was frozen at each visit.

Figure 1 shows snow pits performed close to Scene 1 and 3 during each visit. Note that on 7 December 2014, only a single snow pit is available and refers to both scenes. Snow pits in the vicinity of Scene 1 were generally shallow (Table 1) and composed of a depth hoar layer at the bottom and a high-density rounded grain winds slab snow layer at the surface. One or two high-density melt/ice crust layers and/or ice lenses were present within the snowpack, resulting from mid-winter melt events (see in Reference [17] the Figure 4 and details). Note that this strong stratification between the top and bottom of the snowpack made the snow density measurements a challenge because of the hardness (surface wind slab and melt/ice crust) and the instability (depth hoar) of the snow layers. Because of the artificial compaction of snow, the snow density of the bottom layer is higher in Scene 3. There was still a high snow density observed in February showing that the artificial high-density snow /ice crust made up a large proportion of the lower $10 \mathrm{~cm}$ of the snowpack in Scene 3. However, as the season progressed and metamorphism continued within the snowpack, there was a decrease in the density of the snow /ice crust layers found within the bottom layers. Note that all air temperature measurements below $-6^{\circ} \mathrm{C}$ ensure that the snow was dry during each visit (Table 1). 
Scene 1

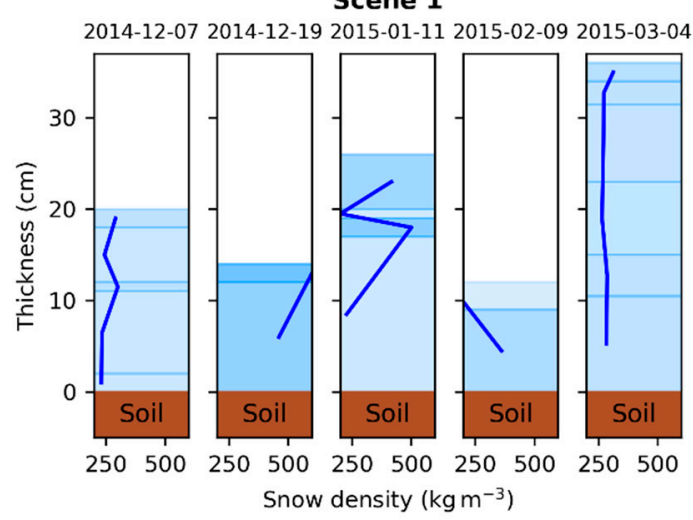

Scene 3

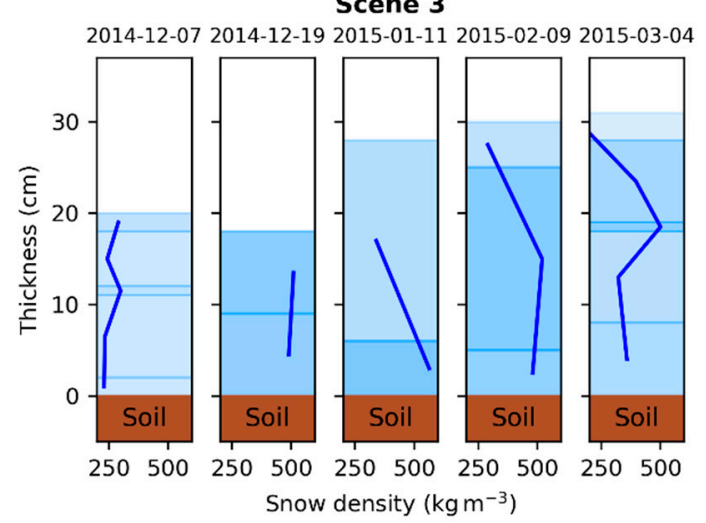

Figure 1. Snow pits measurements in the vicinity of Scene 1 (left) and Scene 3 (right) performed at each visit. Dark blue lines are the snow layer density. Scene 2 was not considered in this study.

Table 1. Snow and air temperature measurements during each visit. "“" means no data. Note that missing data are related to technical issues with instruments.

\begin{tabular}{ccccccc}
\hline \multirow{2}{*}{ Dates } & Snow Depth $\mathbf{( c m )}$ & $\begin{array}{c}\text { Snow Bulk Density } \\
\left(\mathbf{k g ~ m}^{-3} \mathbf{)}\right.\end{array}$ & $\begin{array}{c}\text { Air } \\
\text { Temperature } \\
\left({ }^{\circ} \mathbf{C}\right)\end{array}$ & $\begin{array}{c}\text { Magna Probe Mean Snow } \\
\text { Depth and Standard } \\
\text { Deviation }(\mathbf{c m})\end{array}$ \\
\cline { 2 - 7 } & Scene 1 & Scene 3 & Scene 1 & Scene 3 & & \\
\hline $2014-12-7$ & 20 & 20 & 230 & 230 & -6.6 & $12 \pm 5$ \\
$2014-12-19$ & 14 & 18 & 460 & 490 & -9.0 & - \\
$2015-1-11$ & 26 & 28 & 226 & 563 & -20.2 & $18 \pm 10$ \\
$2015-2-9$ & 12 & 30 & 360 & 480 & -13.9 & $18 \pm 7$ \\
$2015-3-4$ & 36 & 31 & 283 & 358 & -16.8 & $25 \pm 7$ \\
\hline
\end{tabular}

\section{Emission Models}

All three snow microwave emission models and the soil emission model used in this study are already well described in detail (see previously provided references). Accordingly, we only recall here the principal components of each model, the model inputs and adjustments made for this study.

\subsection{WALOMIS}

The WALOMIS [18] coherent snow emission model is based on a wave approach, i.e., solving Maxwell's equation for a multi-layered medium [29,30]. Each layer is characterized by thickness, temperature, and density. The most important simplification in this model is to neglect scattering by snow grains. This assumption is invalid for high microwave frequencies, however, in the case of L-band, scattering by grains is insignificant in comparison with absorption and reflection at the interfaces between layers due to the L-band wavelength being several orders of magnitude larger than snow grain size. Under these assumptions, the vertically and horizontally polarized $T_{\mathrm{B}}$ of a given snowpack is calculated with the propagation-matrix derived from Reference [31].

WALOMIS was initially implemented to investigate the microwave emission at L-band for semi-infinite snow-firn in Antarctica [18,25]. In the case of the Antarctic ice-sheet, the soil emission can be ignored because of the high ice thickness $(>1000 \mathrm{~m})$. Thus, the lowest layer of the model is considered a semi-infinite ice layer. In contrast, in the case of seasonal snowpack, the soil emission is not negligible for the total emission of the snow-covered ground. Therefore, for the present study WALOMIS was adapted to take into account the soil emission from below the snowpack replacing the semi-infinite bottom ice layer by a soil layer characterized by the observed temperature and permittivity.

Because of the high sensitivity of the interference phenomena to the layer thickness with the wave approach (which is not the case with the non-coherent radiative transfer approach), the result obtained for a specific snowpack configuration (i.e., a given set of inputs) may differ considerably from those 
obtained with a slightly different snowpack. To account for the variable nature and the imperfect layering of the snowpack within the footprint of the radiometer, it is essential to average a large number of simulations using inputs that represent natural snow variability. As thousands of simulations are required, it would be impossible to obtain the input profiles from direct measurements. Several studies suggested stochastic methods to generate such profiles from measurements in Antarctica (e.g., Reference $[18,29,32])$. A similar procedure used here is described in Section 4.2. The output of the model is the average $T_{\mathrm{B}}$ from all the generated profiles.

\subsection{DMRT-ML}

The DMRT-MultiLayer (DMRT-ML) is an incoherent model that describes the snowpack as a multilayer medium, where each snow layer is characterized by its thickness, temperature, density, grain optical radius, stickiness parameter, and liquid water content. The model is available from http:/ /gp.snow-physics.science/dmrtml. It is based on the DMRT theory [30]. In this study, stickiness is not investigated because scattering by grains is negligible, and this parameter has no effect at L-band (typically less than $0.1 \mathrm{~K}$ ). Because all the measurements were made in cold conditions with dry snow, the liquid water content was considered to be zero. For each layer, the effective dielectric constant is represented using the first order quasi-crystalline approximation and the Percus-Yevik approximation for spherical grains. The absorption and scattering coefficients are calculated assuming a medium of "ice spheres in air background" and the emission and propagation of radiation through the snowpack are computed using the Discrete Ordinate Method (DISORT: [33]) with 64 streams, which takes multiple scattering between the layers into account, but not the interferences.

\section{3. $L S-M E M L S-1 L$}

The LS-MEMLS [19] model estimates L-band microwave emission from a ground surface covered by a layer of dry snow. This emission model is based on parts of MEMLS, [12] with the assumptions of no absorption and no volume scattering in dry snow, which are applicable to the L-band frequencies in dry snow. Once the interface reflectivities are known, the Kirchhoff coefficients associated with a single (snow) layer above an infinite half-space (ground) are computed to derive $T_{\mathrm{B}}$. Snow is characterized only by its permittivity, controlled by the dry snow density. Schwank et al. [8] assumed a single snow layer with a homogeneous density distribution, which allowed a numerical inversion of the model with minimal a priori information, for purposes of retrieval of snow and ground parameters. Although e.g., Reference [34] applied the model also in a configuration exhibiting a vertical distribution of snow densities, in this study LS-MEMLS is applied in the original one-layer configuration (LS-MEMLS-1L) to evaluate its applicability for snow density retrievals $[8,9]$.

\subsection{Soil Emission Model}

At L-band, soil emission has a significant contribution to the signal emerging from the surface in environments with seasonal snow [35]. Hence, a soil reflectivity model is a prominent component of seasonal snow microwave-emission models. In this study, the soil reflectivity is calculated from the Fresnel equations and the roughness is considered as negligible. A specular soil reflectivity model is used in this study because WALOMIS needs electric field reflectivity between layers, while known rough soil emission models (i.e., Reference [36]) provide only the power reflectivity without phase information. Because the main purpose of this study is to evaluate the performance of snow emission models, it is important that the same soil emission model is used for the three snow emission models in order to avoid any bias in simulations that come from soil emission modelling. The same specular soil reflectivity model is thus used with each of the three snow emission models. The hypothesis of a specular soil is plausible in our case because the root-mean-square height (RMSH: $1.79 \mathrm{~cm}$ and $1.75 \mathrm{~cm}$; see Section 2) of the soil measured with the LiDAR is much smaller than the L-band wavelength $(\mathrm{RMSH}<\lambda / 12)$. 
Fresnel equations calculate the soil reflectivity from the permittivity of the frozen soil and the permittivity of the layer on top (air or snow). Snow permittivity is calculated from snow emission models, but frozen soil permittivity $\left(\varepsilon_{\mathrm{g}}\right)$ was not measured and remains an unknown. Hence, $\varepsilon_{\mathrm{g}}$ was inferred from frozen ground snow-free radiometric measurements taken on 9 November (see Table 1). An iterative process with an increment of 0.1 was used to calculate the frozen soil permittivity that minimized the root-mean-square error (RMSE) between the measured $T_{\mathrm{B}}\left(T_{\mathrm{B} \text { mes }}\right)$, and simulated $T_{\mathrm{B}}$ $\left(T_{\mathrm{B} \text { sim }}\right)$ at vertical $(\mathrm{V}-\mathrm{pol})$ and horizontal polarization $(\mathrm{H}-\mathrm{pol})$ at the four measured incidence angles such that:

$$
R M S E_{\varepsilon g}=\sqrt{\frac{\sum_{i=1}^{N}\left(T_{B \sim, i}^{V-p o l}-T_{B m e s, i}^{V-p o l}\right)^{2}+\left(T_{B \sim, i}^{H-p o l}-T_{B m e s, i}^{H-p o l}\right)^{2}}{2 N}}
$$

The optimization of $\varepsilon_{\mathrm{g}}$ was done on Scene 1 and 3 separately. In this case, $\varepsilon_{\mathrm{g}}$ should be considered as an effective parameter that allows representation of frozen soil emission for the three models, but can also partially compensate for the specular assumption.

\section{Results}

\subsection{Frozen Soil Permittivity}

The optimized $\varepsilon_{\mathrm{g}}$ was calculated from $T_{\mathrm{B}}$ simulations for $\varepsilon_{\mathrm{g}}$ ranging from 1 to 15 and using November snow-free frozen soil parameters. $\mathrm{RMSE}_{\varepsilon g}$ was computed from angular radiometer measurements performed on 1st November 2015 on Scene 1 and 3 at vertical and horizontal polarization (Figure 2). The optimal value of $\varepsilon_{\mathrm{g}}$ was 4.6 and 4.9 for Scene 1 and 3, respectively. RMSE $\mathrm{E}_{\varepsilon g}$ of $10.7 \mathrm{~K}$ and $8.2 \mathrm{~K}$, respectively, was observed for Scene 1 and 3, but an important component of this error was the poor simulation performance at $60^{\circ} \mathrm{V}$-pol (discussed in more detail later). $\mathrm{RMSE}_{\varepsilon g}$ computed without the $T_{\mathrm{B}}$ at $60^{\circ}$ are $6.9 \mathrm{~K}$ and $5.7 \mathrm{~K}$ for an optimized $\varepsilon_{\mathrm{g}}$ of 4.3 and 4.8 for Scene 1 and 3, respectively. The small differences between both sites are not significant, and could be related to differences in soil RMSH, which is not considered in the soil model. These optimized $\varepsilon_{\mathrm{g}}$ were used in the following simulations.

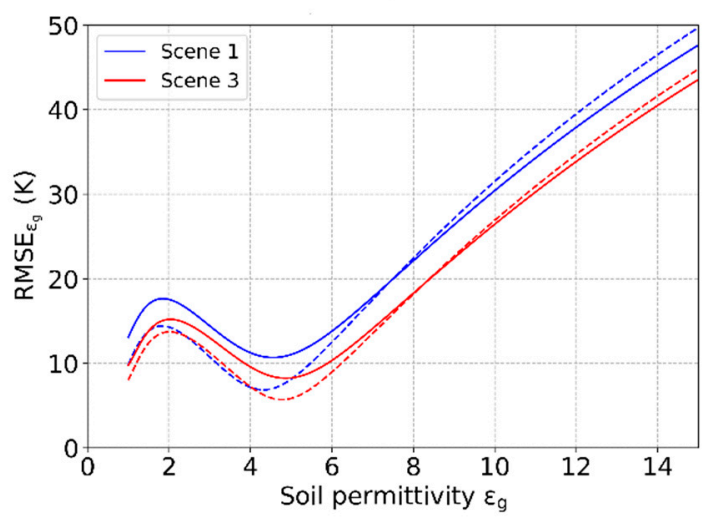

Figure 2. $\mathrm{RMSE}_{\varepsilon \mathrm{g}}$ ) obtained from Dense Media Radiative Transfer-Multi Layer (DMRT-ML) simulations and angular radiometer measurements performed in November 2015 on snow-free frozen soil on Scene 1 (blue) and 3 (red) for different values of soil permittivity $\left(\varepsilon_{\mathrm{g}}\right)$ with a specular soil reflectivity model. $\mathrm{RMSE}_{\varepsilon \mathrm{g}}$ including all incidence angles (solid lines) and without $60^{\circ}$ (dashed lines) are represented.

\subsection{WALOMIS Gaussian Noise Parameterization}

As is true of any model based on the wave approach, the result obtained for a specific snowpack configuration (i.e., a given set of inputs) may differ considerably from those obtained with a slightly different snowpack, which is not the case with the radiative transfer approach. This is due to the high sensitivity of interference phenomena to layer characteristics. Hence, on the basis of Reference [18], 
10,000 snow density profiles were generated by adding a Gaussian noise $\left(\sigma_{\mathrm{d}}\right)$ to the measured density profile and $T_{\mathrm{B}}$ was obtained from the average of 10,000 WALOMIS simulations performed with these profiles.

Figure 3 shows the effect of the Gaussian noise for an example of simulations for Scene 1 on 4 March 2015 with fixed layer thickness. Even with a very high Gaussian noise of $\sigma_{\mathrm{d}}=90 \mathrm{~kg} \mathrm{~m}^{-3}$, the simulations show a wavy angular pattern owing to the high sensitivity of interference phenomena, very different to the measured angular spectrum. These results suggest that for shallow seasonal snow, adding Gaussian noise to density profiles does not reproduce the variability of snow cover within the radiometer field of view.
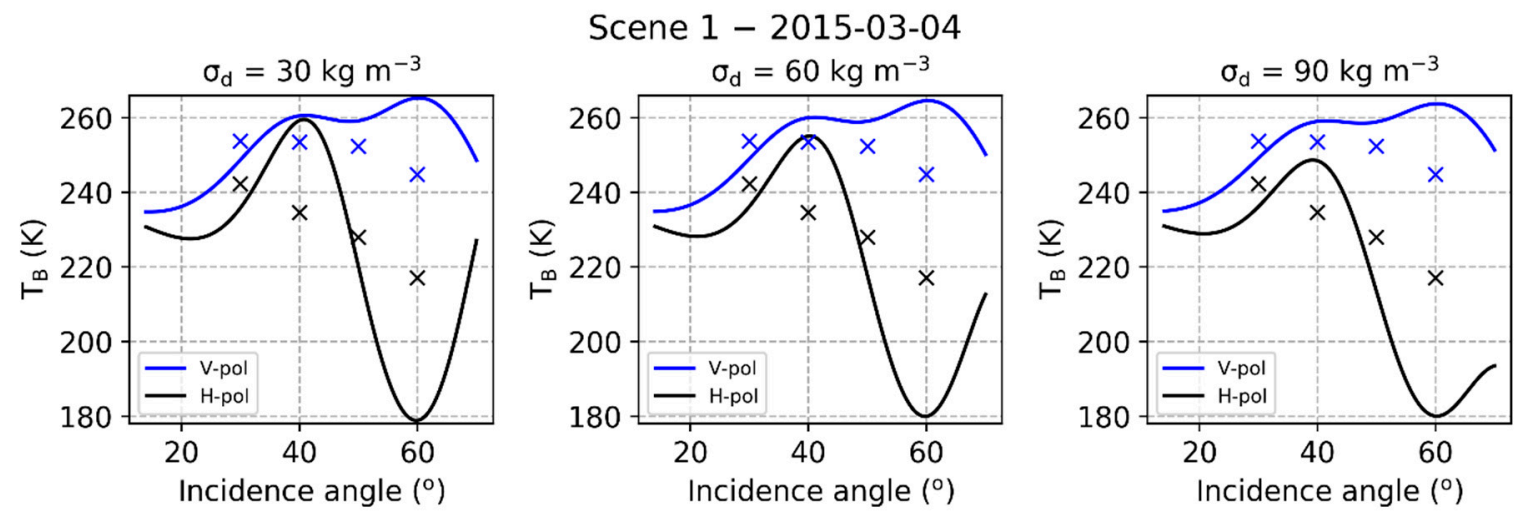

Figure 3. $\mathrm{T}_{\mathrm{B}} \mathrm{V}$-pol (blue) and $\mathrm{T}_{\mathrm{B}} \mathrm{H}$-pol (black) on 4 March 2015 at Scene 1 measured (symbols) and simulated (lines) with the Wave Approach for LOw-frequency MIcrowave emission in Snow (WALOMIS) with added Gaussian noise $\left(\sigma_{\mathrm{d}}\right)$ to the measured density of $30 \mathrm{~kg} \mathrm{~m}^{-3}$ (left), $60 \mathrm{~kg} \mathrm{~m}^{-3}$ (center) and $90 \mathrm{~kg} \mathrm{~m}^{-3}$ (right).

In situ measurements performed during the campaign revealed strong variability in the thickness of internal layers within the snowpack (see Reference [17]), which could better represent interference phenomena in the model. WALOMIS simulations were also performed from 10,000 profiles of layers thickness by adding a Gaussian noise $\left(\sigma_{\mathrm{h}}\right)$ to the measured layer thickness, keeping the measured snow density. Figure 4 shows that with increasing $\sigma_{\mathrm{h}}$, the angular pattern of the simulation gets closer to the $T_{\mathrm{B}}$ measurements. Increasing the variability of layer thickness to $2-4 \mathrm{~cm}$ results in agreement with the $T_{\mathrm{B}}$ observations (Figure 4 ). With a $\sigma_{\mathrm{h}}=2 \mathrm{~cm}$ and $4 \mathrm{~cm}$, the simulated H-pol also capture the $T_{\mathrm{B}}$ decrease with incidence angle. However, contrary to observations which slowly decrease with incidence angle, simulations at V-pol tend to increase with incidence angle, before decreasing at $60^{\circ}$. As expected, because interference phenomena are highly sensitive to optical path-length across layers, a Gaussian noise of $\sigma_{\mathrm{h}}=2 \mathrm{~cm}$, was found to give the best agreement with measurements and was used for the subsequent simulations. 

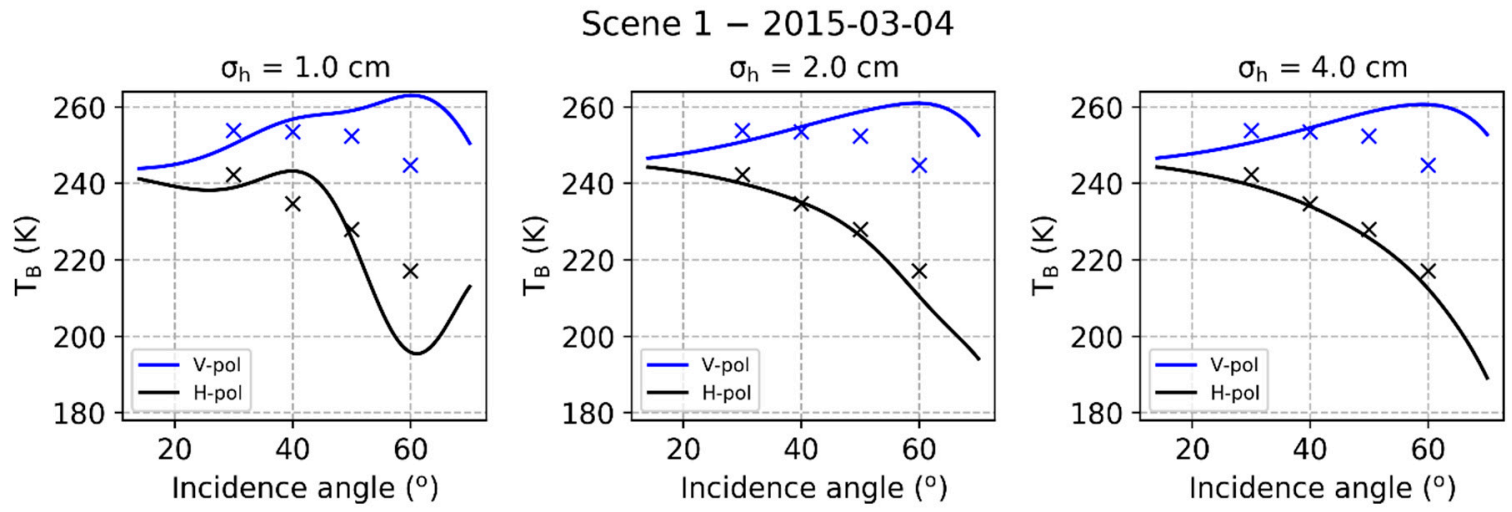

Figure 4. $\mathrm{T}_{\mathrm{B}} \mathrm{V}$-pol (blue) and $\mathrm{T}_{\mathrm{B}} \mathrm{H}$-pol (black) for 4 March 2015 at Scene 1 measured (symbols) and simulated (lines) with WALOMIS with added Gaussian noise $\left(\sigma_{\mathrm{h}}\right)$ to the measured layer thickness of $1 \mathrm{~cm}$ (left), $2 \mathrm{~cm}$ (center) and $4 \mathrm{~cm}$ (right).

\subsection{Footprint Integration}

Because of the large antenna full beamwidth $\left(30^{\circ}\right)$ and the footprint geometry of the surface-based radiometer, the simulated $T_{\mathrm{B}}$ of a single directional incidence angle $(\theta)$ might not be representative of the measured $T_{B}$ over a large footprint, especially at higher incidence angles [37]. Hence, in this study, a weighting function was computed to estimate the integrated $T_{\mathrm{B}}$ within the footprint for a range of incidence angles. For this estimation, the area included in $\theta \pm 15^{\circ}$ was considered. A Gaussian weighting was applied to $\theta$ with a standard deviation of $7.5^{\circ}$ in order to represent the antenna directional power sensitivity pattern. Then, a factor $1 / r^{2}$, with $\mathrm{r}$ the distance from the radiometer, was applied to the obtained coefficients to attenuate the contribution as a function of the location within the footprint. The coefficients used for the weighting are illustrated in Figure 5, normalized by the maximum.
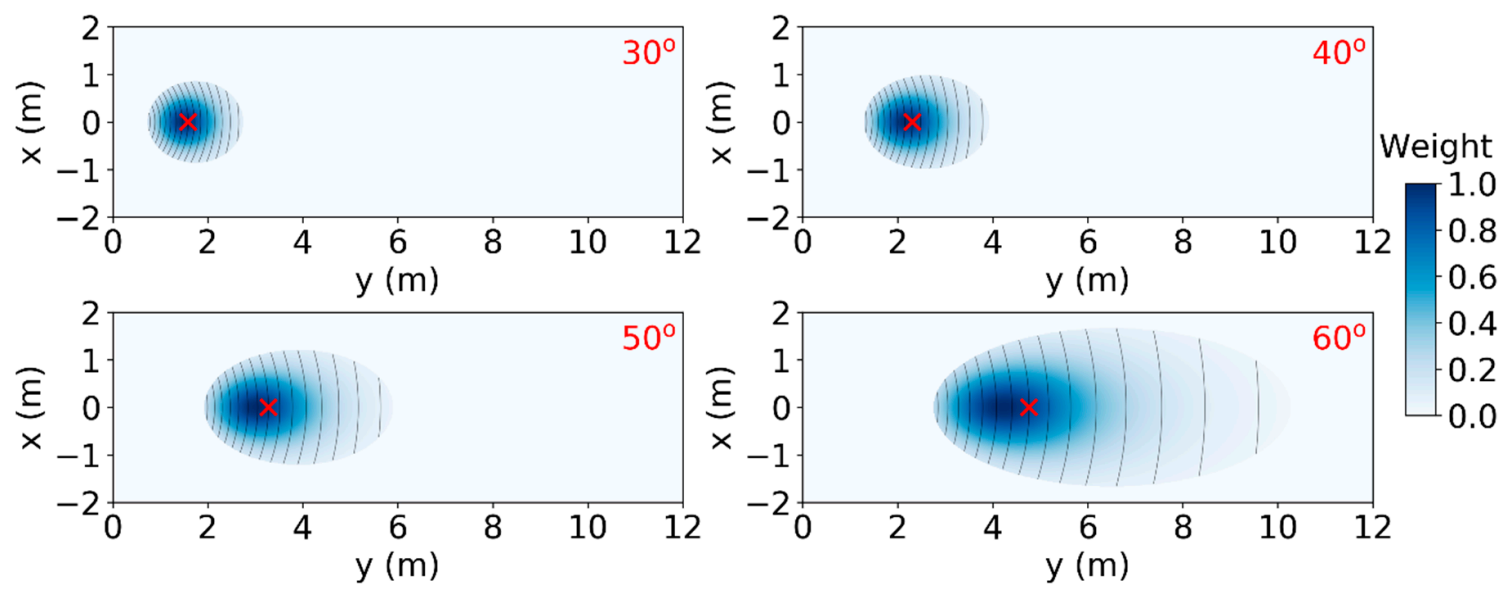

Figure 5. Weight relative to maximum diagram where $X$ and $Y$ are coordinates (in meters) on the field from the radiometer $(0,0)$. Red crosses are the incidence angles of the antenna footprint center. Grey lines for incidence angles inside the footprint by $2^{\circ}$ step.

When the weighting function was applied to the simulations of the three snow emission models at Scene 3 on 4 March 2015, there is a decrease of $T_{\mathrm{B}}$ at both H-pol and V-pol mostly at incidence angles higher than $55^{\circ}$ (Figure 6). This decrease in $T_{\mathrm{B}}$ slightly improved the results for all three models at high incidence angles, thus it was used in the following simulations. 

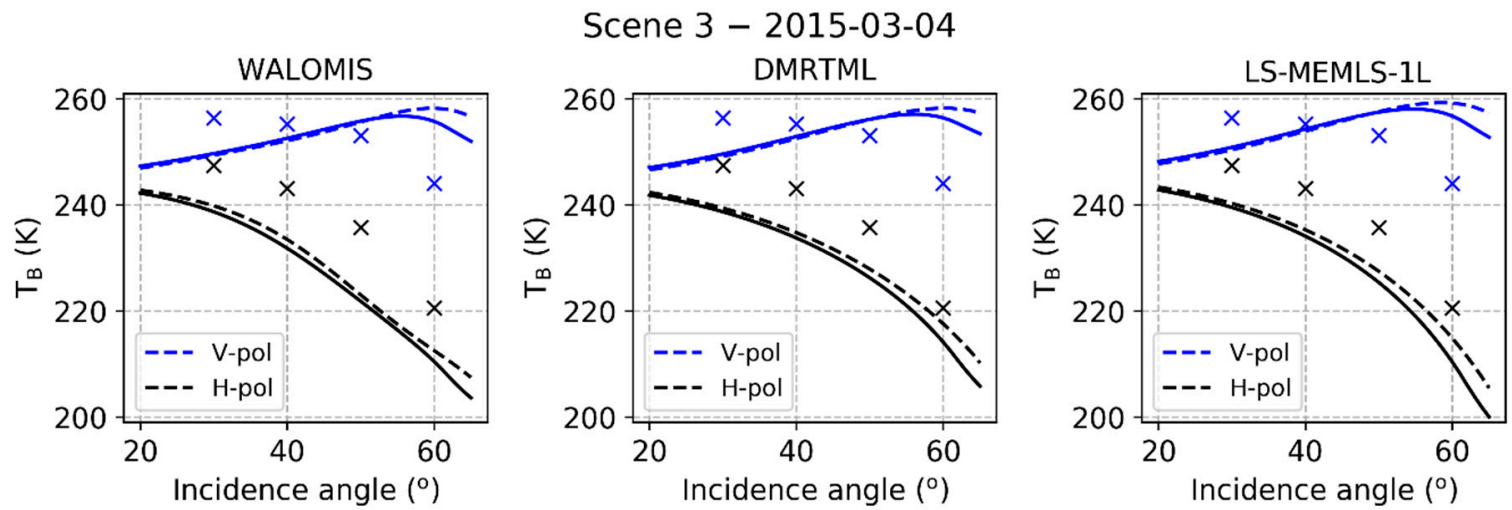

Figure 6. $\mathrm{T}_{\mathrm{B}} \mathrm{V}$-pol (blue) and $\mathrm{T}_{\mathrm{B}} \mathrm{H}$-pol (black) measured (symbols) and simulated using non-weighted (dashed) and weighted (lines) signal within the footprint; with WALOMIS (left), DMRT-ML (center) and LS-MEMLS-1L (right) at Scene 3 for 4 March 2015.

\subsection{Snow Emission Model Intercomparison}

The effect of dry snow at L-band is mostly related to refraction and impedance matching [16]. Impedance matching by dry snow reduces dielectric gradients and consequently increases thermal emission of the scene, while refraction caused by the snow layer in contact with the ground surface leads to a steeper incidence angle at the ground surface in comparison with the observation angle [16]. The impact is in general higher at $\mathrm{H}$-pol, since at $\mathrm{V}$-pol these effects are partly compensatory, and even fully compensatory around an incidence angle of $51^{\circ}$. At $\mathrm{H}$-pol, the effect of snow typically increases with incidence angle. At the plot scale, the presence of snow can change $T_{\mathrm{B}}$ at $\mathrm{H}$-pol from $5 \mathrm{~K}$ at $30^{\circ}$ up to $20 \mathrm{~K}$ at $60^{\circ}$ [17]. The specular soil reflectivity model with optimized permittivity and the optimized weighting function were used to simulate the $T_{\mathrm{B}}$ at the Scene 1 and 3 and for the six sampling periods with the three snow emission models (Figure 7). The three models show very similar overall RMSE at V-pol and $\mathrm{H}$-pol with values ranging between $7.2 \mathrm{~K}$ and 10.5 K. LS-MEMLS-1L gives lower RMSE at H-pol while DMRT-ML gives slightly better results at V-pol. Note that for the three models and both polarizations, the RMSE increases with increasing incidence angle (Table 2). The worst results are obtained at $60^{\circ}$, which has a strong impact on the overall RMSE (noted "All" in Table 2). It is thus not possible to state that a specific snow emission model gives better results overall. Nevertheless, at $50^{\circ}$ and $60^{\circ}$, LS-MEMLS- $1 \mathrm{~L}$ clearly underestimates the variability of $T_{\mathrm{B}} \mathrm{H}-$ pol, with a standard deviation of the simulations much lower than the standard deviation of observations. Simulations at $60^{\circ}$ ranged between $203.9 \mathrm{~K}$ and $213.9 \mathrm{~K}$, while the measured $T_{\mathrm{B}} \mathrm{H}$-pol ranged between $192.8 \mathrm{~K}$ and $225.8 \mathrm{~K}$. On the other hand, the standard deviations of WALOMIS and DMRT-ML simulations at $T_{\mathrm{B}} \mathrm{H}-\mathrm{pol}$ are much closer to the measurements (Table 3 ). These results suggest that snow layers significantly impact the $T_{\mathrm{B}} \mathrm{H}$-pol. The multi-layer model configurations are able to better capture this effect, but the complex interaction of the radiation within the layers and the difficulty to precisely measure the snow layer characteristics in the field at the meter scale (footprint) leads to an overall RMSE comparable to LS-MEMLS-1L applied in a 1-layer configuration. We thus face the problem where more complex and more sensitive radiometric models require precise in situ information for comprehensive evaluation, a condition that will provide limitations for more general use, especially at the satellite scale. 

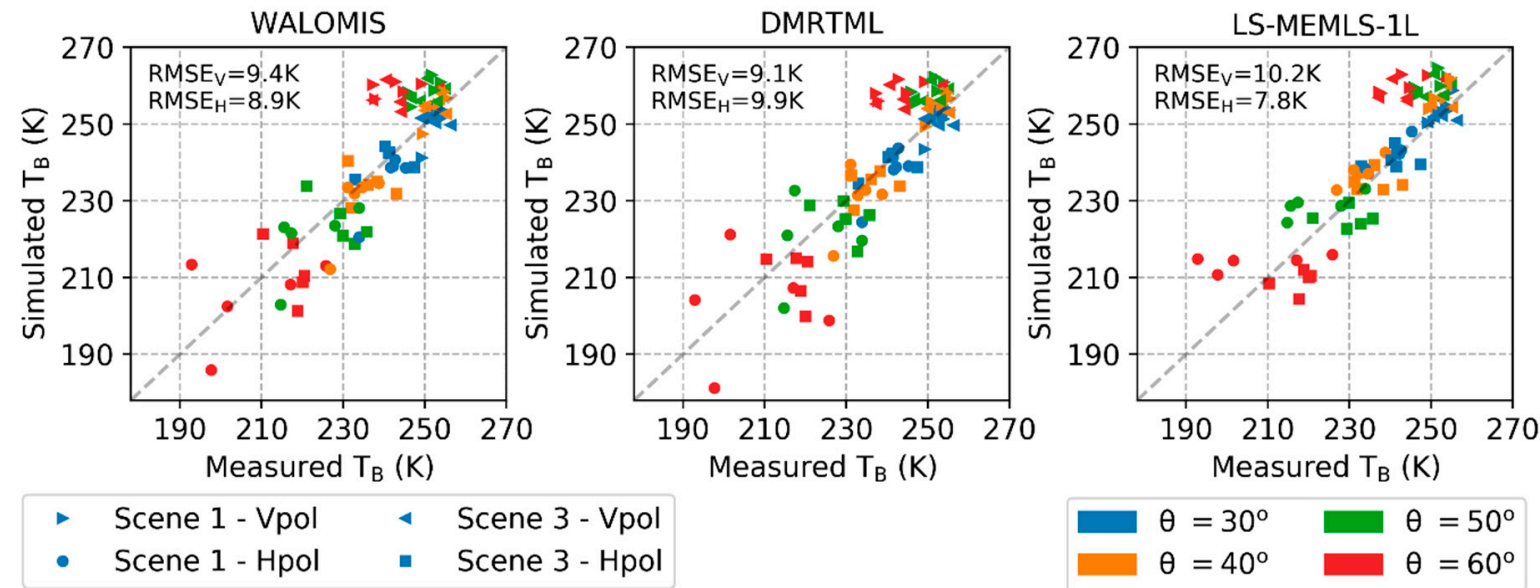

- Scene 1 - Vpol 4 Scene $3-$ Vpol

- Scene $1-\mathrm{Hpol}$ - Scene $3-\mathrm{Hpol}$

$\theta=40^{\circ}$

Figure 7. $T_{\mathrm{B}}$ simulated from WALOMIS (left), DMRT-ML (center) and LS-MEMLS-1L (right) for Scene 1 and 3 at V-pol and H-pol (symbols) and at four incidence angles (colors).

Table 2. Root-mean-square height (RMSE) of all the dates and Scene 1 and 3 together. "All" is the RMSE calculated with incidence angles of $30^{\circ}, 40^{\circ}, 50^{\circ}$ and $60^{\circ}$.

\begin{tabular}{lcccccccccc}
\hline & \multicolumn{4}{c}{ RMSE for $\mathbf{T}_{\mathbf{B}} \mathbf{V}$-pol (K) } & \multicolumn{4}{c}{ RMSE for $\mathbf{T}_{\mathbf{B}} \mathbf{H}$-pol (K) } \\
\hline & $\mathbf{3 0}^{\circ}$ & $\mathbf{4 0}^{\circ}$ & $\mathbf{5 0}^{\circ}$ & $\mathbf{6 0}^{\circ}$ & $\mathbf{A l l}$ & $\mathbf{3 0}^{\circ}$ & $\mathbf{4 0}^{\circ}$ & $\mathbf{5 0}^{\circ}$ & $\mathbf{6 0}^{\circ}$ & All \\
\hline WALOMIS & 4.6 & 2.9 & 7.8 & 15.4 & 9.1 & 6.9 & 7.8 & 10.2 & 12.9 & 9.7 \\
DMRT-ML & 4.1 & 2.6 & 7.7 & 14.8 & 8.8 & 5.9 & 7.0 & 11.0 & 15.7 & 10.5 \\
LS-MEMLS-1L & 2.5 & 3.8 & 9.2 & 16.1 & 9.6 & 3.7 & 4.3 & 7.3 & 11.2 & 7.2 \\
\hline
\end{tabular}

Table 3. Standard deviation (Std) of all the dates and, Scene 1 and 3 together. "All" is the Std calculated with incidence angles of $30^{\circ}, 40^{\circ}, 50^{\circ}$ and $60^{\circ}$.

\begin{tabular}{lcccccccc}
\hline & \multicolumn{3}{c}{ Std for $\mathbf{T}_{\mathbf{B}} \mathbf{V}$-pol (K) } & \multicolumn{3}{c}{ Std for $\mathbf{T}_{\mathbf{B}} \mathbf{H}-$ pol (K) } \\
\hline & $\mathbf{3 0}^{\circ}$ & $\mathbf{4 0}^{\circ}$ & $\mathbf{5 0}^{\circ}$ & $\mathbf{6 0}^{\circ}$ & $\mathbf{3 0}^{\circ}$ & $\mathbf{4 0}^{\circ}$ & $\mathbf{5 0}^{\circ}$ & $\mathbf{6 0}^{\circ}$ \\
\hline WALOMIS & 3.8 & 3.1 & 2.6 & 2.5 & 6.7 & 7.5 & 8.1 & 10.1 \\
DMRT-ML & 3.1 & 2.5 & 2.3 & 2.4 & 5.6 & 6.8 & 8.6 & 11.1 \\
LS-MEMLS-1L & 2.6 & 2.5 & 2.4 & 2.4 & 2.9 & 2.9 & 2.8 & 2.8 \\
Measures & 2.3 & 2.7 & 2.9 & 4.2 & 5.3 & 7.8 & 11.3 & 13.8 \\
\hline
\end{tabular}

\section{Discussion}

\subsection{Soil Permittivity Parameterization}

The optimized values of frozen soil permittivity are close to other studies $[16,17,35,38,39]$. Rautiainen et al. [35] obtained L-band real part soil permittivity values between 3.3 to 3.8 in boreal forest frozen soils; Schwank et al. [16] showed that for L-band, the real part of the frozen soil permittivity varies from 3.5 to 4.5 , while Hallikainen et al. [38] showed that it varies from 5 to 8 in the 10 to $18 \mathrm{GHz}$ frequency range. At the same frequency range, Mironov et al. [39] developed a temperature dependent permittivity model and showed that the permittivity could vary from 3 to 4.5 for a frozen soil at $-25{ }^{\circ} \mathrm{C}$. The optimized values are similar to the ones obtain at the same site ([17]; $\left.\varepsilon_{\mathrm{g}}=5.1\right)$, but using a two parameter ( $\varepsilon_{\mathrm{g}}$ and snow density) retrieval method [8]. The plausible optimized $\varepsilon_{\mathrm{g}}$ values thus show that the assumption of a flat soil at L-band was reasonable for our site and the impact of soil roughness is reasonably included in the $\varepsilon_{\mathrm{g}}$. However, in this study, soil emission was empirically parameterized to minimize its impact on the simulation of snow covered ground, but it remains that the snow-free frozen soil RMSE are similar to the snow simulations. In particular, Figure 6 shows that at V-pol, there is a clear underestimation of the $T_{\mathrm{B}}$ at an incidence angle of $30^{\circ}$, while there is an overestimation of $T_{\mathrm{B}}$ at higher incidence angle $\left(50^{\circ}\right.$ and $\left.60^{\circ}\right)$. There is thus an opposite trend in the 
angular spectrum between the measurements and the observations, an effect most likely related to the soil model. It should be note that those error impact substantially the results with snow-covered surface. Simulations and observations at V-pol will have to be investigated further.

\subsection{WALOMIS Gaussian Noise Parameterization}

This study shows that an approach developed by Reference [18], which applies Gaussian noise to in situ snow density measurements to estimate $T_{\mathrm{B}}$ variability is insufficient to smooth the snow layer interference phenomena in WALOMIS. However, Gaussian noise applied to snow depth layer thickness of $\sigma_{\mathrm{h}}=2 \mathrm{~cm}$ leads to an angular spectrum comparable to the observations. A value of $\sigma_{\mathrm{h}}=2 \mathrm{~cm}$ is plausible considering the high standard deviation of snow depth in the area and the variable internal layering of the snowpack. Snow depth surveys around the area suggest that despite the surface appearing relatively homogeneous, the standard deviation of the snow depth is in the range of 28 to $56 \%$ (Table 1). The high variability in snow depth is related to wind redistribution, a key process in this prairie environment [40]. Strong winds also lead to a high snow density layer observed at top of the snowpack due to compaction processes [41], thus resulting in the optimized snow depth layer thickness variability $\sigma_{\mathrm{h}}$ of $2 \mathrm{~cm}$ at the plot scale.

\subsection{Footprint Integration}

Roy et al. [37] showed that spatially distributed surface-based radiometer observations within a SMOS pixel gives constantly lower $T_{\mathrm{B}}$ (between 8.5 and $22.9 \mathrm{~K}$ ) than SMOS observations at $60^{\circ}$ $\mathrm{V}$-pol (not apparent at lower incidence angles). It was hypothesized that these discrepancies were due to the large beamwidth $\left(30^{\circ}\right)$ of the surface-based radiometer, which produced an incidence angle in the far range of up to $75^{\circ}$. This may exaggerate the influence of high incidence angles on reducing the magnitude of $\mathrm{V}$-pol $T_{\mathrm{B}}$. The calculation of the weighted footprint integration in this paper shows that the effective incidence angle can explain a small part of the ground-based radiometer bias to lower $T_{\mathrm{B}}$ at $60^{\circ} \mathrm{V}$-pol (Figure 6). For the three models, RMSE was reduced $2.4 \mathrm{~K}$ at $60^{\circ} \mathrm{V}$-pol because of the footprint integration, but no clear improvement was observed at H-pol. The footprint integration cannot fully account for the entire difference between simulations and measurements at higher incidence angles. Thus, part of the difference may be the result of the sky contribution (low $T_{\mathrm{B}}$ ) captured by antenna side lobes.

\subsection{Snow Emission Model Intercomparison}

Results show that all models give similar overall RMSE values between $7.2 \mathrm{~K}$ and $10.5 \mathrm{~K}$. It is thus difficult to identify a preferred model for this environment. Those snow-covered RMSE are very similar to snow-free RMSE, which suggest that a large part of the errors come from the soil parameterization (see Section 5.1). However, our results suggest that the multi-layer models, DMRT-ML and WALOMIS, are able to better simulate the range of observed $T_{\mathrm{B}}$ compared to the one-layer model. DMRT-ML and WALOMIS simulations are similar, and suggest that the interference phenomena, simulated by WALOMIS, have a marginal impact on the simulations. Leduc-Leballeur et al. [14] showed that the coherence effect considered in WALOMIS significantly improve the simulation for the semi-infinite snow layered medium in Antarctica, which is not the case for shallow seasonal snowpack. It seems that DMRT-ML, by considering the refraction between layers incorporate the main features needed to reproduce variations in the $T_{\mathrm{B}}$ similar to the observations. However, the snowpack during the winter was shallow with very strong meter scale spatial variability and a stratigraphy that made the snow density measurements challenging to document within the field of view of the radiometer (Table 1). Furthermore, because of the several melt/refreeze events that occurred during the winter several ice layers were present in the snowpack resulting in substantial spatial variability. Because of this high spatial variability in the presence of ice layers and snow density within the snowpack, it is unlikely that individual snow pit measurements are representative of the radiometer footprint, and thus a further source of model uncertainty. Therefore, it is difficult to precisely quantify the effect of coherence in 
an ice layer, even in a relatively controlled experiment such as that described. A similar experiment but with deeper and more homogeneous snow could help to improve our understanding of snow layer effects on L-band emission. The higher complexity of simulations with WALOMIS may not be necessary, unless coherence and layering effects are very strong.

Although the one-layer model does not capture stratigraphy and coherence effects captured in the more detailed multi-layered models, the overall performance was similar. Hence, in a snow density inversion scheme such as that proposed by Reference [8], the one-layer model is a practical solution because it includes only a small number of free parameters, which is almost a prerequisite to achieve unique values of respective retrievals.

\section{Summary and Conclusions}

Recent studies show the non-negligible impact of snow on L-band emission $[8,17,19]$ even when the snowpack is shallow. In this study, the Wave Approach for LOw-frequency MIcrowave emission in Snow was adapted and parameterized for seasonal snow using ground-based L-band radiometer observations in a prairie environment. A specular soil reflectivity model was added to WALOMIS, and frozen soil permittivity $\left(\varepsilon_{\mathrm{g}}\right)$ of 4.3 and 4.8 used for Scene 1 and 3 , respectively, was estimated using an optimisation scheme that compared, observed and simulated $T_{B}$ (DMRT-ML) from snow free frozen ground measurements.

Gaussian noise of snow depth layers of $\sigma_{\mathrm{h}}=2 \mathrm{~cm}$ obtained a comparable multi-angular $T_{\mathrm{B}}$ response but still underestimated the observations at $\mathrm{H}$-pol. The same simulations also underestimated at lower incidence angles and overestimated at higher incidence angles compared to V-pol observations. The calculation of a weighted footprint integration shows that the effective incidence angle can explain part, but not all of the ground-based radiometer bias to lower $T_{\mathrm{B}}$ at $60^{\circ} \mathrm{V}$-pol, but no clear improvement was observed at H-pol. The WALOMIS simulations were then compared to two other radiative transfer models, the DMRT-ML and a simplified adaptation of MEMLS for L-band (LS-MEMLS-1L), used in a single-layer configuration. RMSE between simulated and measured $T_{\mathrm{B}}$ were similar for the three models with overall RMSE between 7.2 and 10.5 K. However, WALOMIS and DMRT-ML were able to better reproduce the range of $T_{\mathrm{B}}$ of the observations at higher $\mathrm{V}$-pol incidence angles $\left(50^{\circ}\right.$ and $\left.60^{\circ}\right)$ and across all incidence angles at $\mathrm{H}$-pol.

The impact of snow on surface emission at L-band is relatively small compared to higher frequencies, where the wavelength is similar to snow grain size, inducing scattering. However, there is still valuable and complementary snow information in L-band observations, such as sensitivity to snow density [9] and ice layers [6]. Hence, it is important to develop and assess existing emission models that will help to better quantify these different effects for applications such as the observation of the soil freeze/thaw status. In this study, an effort was made to develop and parameterize WALOMIS for seasonal snow. While the results of all three models are similar, the wave approach of WALOMIS suggests that it is an appropriate new tool to better understand and model L-band emission when interference and snow layering is present.

Author Contributions: A.R. (Alexandre Roy), P.T., C.D., A.B., A.R. (Alain Royer) and T.R. designed the study. A.R. (Alexandre Roy), P.T., C.D., J.L., A.B., and T.R. collected the data. M.L.-L. and A.R. (Alexandre Roy) performed the simulation and the analysis. G.P., J.L. and M.S. developed the softwares. All authors contributed in editing the manuscript.

Funding: The authors would like to thank the Canadian Space Agency (CSA), the Natural Sciences and Engineering Research Council of Canada (NSERC), the French Space Agency (CNES-TOSCA SMOS program), the European Space Agency (ESA) and the Conseil Franco-Québécois de Coopération Universitaire (CFQCU) for their financial support.

Acknowledgments: Thanks to Laurent Bergeron (Université de Sherbrooke) for performing some of the simulations. We would like to thank Erika Tetlock, Craig Smith, Lauren Arnold (Environment and Climate Change Canada), Matthew Williamson (University of Guelph) and the staff at the University of Saskatchewan's Kernen Crop Research Farm for their contributions to the field work.

Conflicts of Interest: The authors declare no conflict of interest. 


\section{References}

1. Kerr, Y.H.; Waldteufel, P.; Wigneron, J.P.; Delwart, S.; Cabot, F.; Boutin, J.; Escorihuela, M.-J.; Font, J.; Reul, N.; Gruhier, C.; et al. The SMOS mission: New tool for monitoring key elements of the global water cycle. Proc. IEEE 2010, 98, 666-687. [CrossRef]

2. Lagerloef, G.; deCharon, A.; Lindstrom, E. Ocean salinity and the Aquarius/SAC-D mission: A new frontier in ocean remote sensing. Mar. Technol. Soc. J. 2013, 47, 26-30. [CrossRef]

3. SMAP Handbook, Mapping Soil Moisture and Freeze/Thaw from Space. Available online: https://smap.jpl.nasa.gov/system/internal_resources/details/original/178_SMAP_Handbook_FINAL_ 1_JULY_2014_Web.pdf (accessed on 5 September 2018).

4. Rautiainen, K.; Parkkinen, T.; Lemmetyinen, J.; Schwank, M.; Wiesmann, A.; Ikonen, J.; Derksen, C.; Davydov, S.; Davydova, A.; Boike, J.; et al. SMOS prototype algorithm for detecting autumn soil freezing. Remote Sens. Environ. 2016, 180, 346-360. [CrossRef]

5. Rautiainen, K.; Lemmetyinen, J.; Schwank, M.; Kontu, A.; Ménard, C.B.; Mätzler, C.; Drusch, M.; Wiesmann, A.; Ikonen, J.; Pulliainen, J. Detection of soil freezing from L-band passive microwave observations. Remote Sens. Environ. 2014, 147, 206-218. [CrossRef]

6. Roy, A.; Royer, A.; Derksen, C.; Brucker, L.; Langlois, A.; Mialon, A.; Kerr, Y.H. Evaluation of Spaceborne L-Band Radiometer Measurements for Terrestrial Freeze/Thaw Retrievals in Canada. IEEE J. Sel. Top. Appl. Earth Obs. Remote Sens. 2015, 8, 4442-4459. [CrossRef]

7. Derksen, C.; Xu, X.; Dunbar, S.R.; Colliander, A.; Kim, Y.; Kimball, J.S.; Black, T.A.; Euskirchen, E.; Langlois, A.; Loranty, M.M.; et al. Retrieving landscape freeze/thaw state from Soil Moisture Active Passive (SMAP) radar and radiometer measurements. Remote Sens. Environ. 2017, 194, 48-62. [CrossRef]

8. Schwank, M.; Mätzler, C.; Wiesmann, A.; Wegmüller, U.; Pulliainen, J.; Lemmetyinen, J.; Drusch, M. Snow density and ground permittivity retrieved from L-band radiometry: A synthetic analysis. IEEE J. Sel. Top. Appl. Earth Observ. Remote Sens. 2015, 8, 3833-3845. [CrossRef]

9. Lemmetyinen, J.; Schwank, M.; Rautiainen, K.; Kontu, A.; Parkkinen, T.; Mätzler, C.; Wiesmann, A.; Wegmüller, U.; Derksen, C.; Toose, P.; et al. Snow density and ground permittivity retrieved from L-Band radiometry: Application to experimental data. Remote Sens. Environ. 2016, 180, 377-391. [CrossRef]

10. Kaleschke, L.; Tian-Kunze, X.; Maaß, N.; Mäkynen, M.; Drusch, M. Sea ice thickness retrieval from SMOS brightness temperatures during the Arctic freeze-up period. Geophys. Res. Lett. 2012, 39, L05501. [CrossRef]

11. Wigneron, J.-P.; Kerr, Y.; Waldteufel, P.; Saleh, K.; Escorihuela, M.-J.; Richaume, P.; Schwank, M. L-band microwave emission of the biosphere (L-MEB) model: Description and calibration against experimental data sets over crop fields. Remote Sens. Environ. 2007, 107, 639-655. [CrossRef]

12. Wiesmann, A.; Mätzler, C. Microwave emission model of layered snowpacks. Remote Sens. Environ. 1999, 70, 307-316. [CrossRef]

13. Tsang, L.; Kong, J.A.; Ding, K.-H. Scattering of Electromagnetic Waves, Vol. 1: Theories and Applications; Wiley-Interscience: New York, NY, USA, 2000.

14. Picard, G.; Brucker, L.; Roy, A.; Dupont, F.; Fily, M.; Royer, A.; Harlow, C. Simulation of the microwave emission of multilayered snowpacks using the Dense Media Radiative transfer theory: The DMRT-ML model. Geosci. Model Dev. 2013, 6, 1061-1078. [CrossRef]

15. Pulliainen, J.T.; Grandell, J.; Hallikainen, M.T. HUT snow emission model and its applicability to snow water equivalent retrieval. IEEE Trans. Geosci. Remote Sens. 1999, 37, 1378-1390. [CrossRef]

16. Schwank, M.; Rautiainen, K.; Mätzler, C.; Stähli, M.; Lemmetyinen, J.; Pulliainen, J.; Vehviläinen, J.; Kontu, A.; Ikonen, J.; Ménard, C.B.; et al. Model for microwave emission of a snow-covered ground with focus on L band. Remote Sens. Environ. 2014, 154, 180-191. [CrossRef]

17. Roy, A.; Toose, P.; Williamson, M.; Rowlandson, T.; Derksen, C.; Royer, A.; Berg, A.A.; Lemmetyinen, J.; Arnold, L. Response of L-Band brightness temperatures to freeze/thaw and snow dynamics in a prairie environment from ground-based radiometer measurements. Remote Sens. Environ. 2017, 191, 67-80. [CrossRef] 
18. Leduc-Leballeur, M.; Picard, G.; Milaon, A.; Arnaud, L.; Lefebvre, E.; Possenti, P.; Kerr, Y.H. Modeling L-band brightness temperature at dome $\mathrm{C}$ in Antarctica and comparison with SMOS observations. IEEE Trans. Geosci. Remote Sens. 2015, 53, 4022-4032. [CrossRef]

19. Naderpour, R.; Schwank, M.; Mätzler, C. Davos-Laret Remote Sensing Field Laboratory: 2016/2017 Winter Season L-Band Measurements Data-Processing and Analysis. Remote Sens. 2017, 9, 1185. [CrossRef]

20. Hofer, R.; Mätzler, C. Investigations on snow parameters by radiometry in the 3- to 60-mm wavelength Region. J. Geophys. Res. 1980, 85, 453-460. [CrossRef]

21. Schwank, M.; Stähli, M.; Wydler, H.; Leuenberger, J.; Mätzler, C.; Member, S.; Flühler, H. Microwave L-Band Emission of Freezing Soil. IEEE Trans. Geosci. Remote Sens. 2004, 42, 1252-1261. [CrossRef]

22. Mätzler, C. Applications of the interactions of micowaves with natural snow cover. Remote Sens. Rev. 1987, 2, 259-392. [CrossRef]

23. Montpetit, B.; Royer, A.; Roy, A.; Langlois, L.; Derksen, D. Snow microwave emission modeling of ice lenses within a snowpack using the microwave emission model for layered snowpacks. IEEE Trans. Geosci. Remote Sens. 2013, 51, 4705-4717. [CrossRef]

24. Rees, A.; Lemmetyinen, J.; Derksen, C.; Pulliainen, J.; English, M. Observed and modelled effects of ice lens formation on passive microwave brightness temperatures over snow covered tundra. Remote Sens. Environ. 2010, 114, 116-126. [CrossRef]

25. Leduc-Leballeur, M.; Picard, G.; Macelloni, G.; Arnaud, L.; Brogioni, M.; Mialon, A.; Kerr, Y.H. Influence of snow surface properties on L-band brightness temperature at Dome C, Antarctica. Remote Sens. Environ. 2017, 199, 427-436. [CrossRef]

26. Chabot, M.; Lindsay, J.; Rowlandson, T.; Berg, A.A. Comparing the Use of Terrestrial LiDAR Scanners and Pin Profilers for Deriving Agricultural Roughness Statistics. Can. J. Remote Sens. 2018, 1-16. [CrossRef]

27. Lindsay, J.B. Whitebox GAT: A case study in geomorphometric analysis. Comput. Geosci. 2016, 95, 75-84. [CrossRef]

28. Toose, P.; Roy, A.; Solheim, F.; Derksen, C.; Royer, A.; Walker, A. Radio frequency interference mitigating hyperspectral L-band radiometer. Geosci. Instrum. Method Data Syst. 2017, 6, 39-51. [CrossRef]

29. West, R.D.; Winebrenner, D.P.; Tsang, L.; Rott, H. Microwave emission from density-stratified Antarctic firn at $6 \mathrm{~cm}$ wavelength. J. Glaciol. 1996, 42, 63-76. [CrossRef]

30. Tsang, L.; Kong, J.A. Scattering of Electromagnetic Waves, Vol. 3: Advanced Topics; Wiley-Interscience: Paris, France, 2001.

31. Tsang, L.; Kong, J.; Shin, R. Theory of Microwave Remote Sensing; Wiley-Interscience: New York, NY, USA, 1987.

32. Tan, S.; Aksoy, M.; Brogioni, M.; Macelloni, G.; Durand, M.; Jezek, K.C.; Wang, T.-L.; Tsang, L.; Johnson, J.T.; Drinkwater, M.R.; et al. Physical models of layered polar firn brightness temperatures from $0.5 \mathrm{GHz}$ to 2 GHz. IEEE J. Sel. Top. Appl. Earth Obs. Remote Sens. 2015, 8, 3681-3691. [CrossRef]

33. Jin, Y. Electromagnetic Scattering Modelling for Quantitative Remote Sensing; World Scientific: Singapore, 1994.

34. Naderpour, R.; Schwank, M.; Mätzler, C.; Lemmetyinen, J.; Steffen, K. Snow Density and Ground Permittivity Retrieved From L-Band Radiometry: A Retrieval Sensitivity Analysis. IEEE J. Sel. Top. Appl. Earth Obs. Remote Sens. 2017, 10, 3148-3161. [CrossRef]

35. Rautiainen, K.; Lemmetyinen, J.; Pulliainen, J.; Vehvilainen, J.; Drusch, M.; Kontu, A.; Kainulainen, J.; Seppänen, J. L-band radiometer observations of soil processes in boreal and subarctic environments. IEEE Trans. Geosci. Remote Sens. 2012, 50, 1483-1497. [CrossRef]

36. Wegmüller, U.; Mätzler, C. Rough bare soil reflectivity model. IEEE Trans. Geosci. Remote 1999, 37, $1391-1395$. [CrossRef]

37. Roy, A.; Toose, P.; Derksen, C.; Rowlandson, T.; Berg, A.; Lemmetyinen, J.; Royer, A.; Tetlock, E.; Helgason, W.; Sonnentag, O. Spatial Variability of L-Band Brightness Temperature during Freeze/Thaw Events over a Prairie Environment. Remote Sens. 2017, 9, 894. [CrossRef]

38. Hallikainen, M.T.; Ulaby, F.T.; Dobson, M.C.; El-Rayes, M.A.; Wu, L.-K. Microwave dielectric behavior of wet soil-Part I: Empirical models and experimental observations. IEEE Trans. Geosci. Remote Sens. 1985, GE-23, 25-34. [CrossRef]

39. Mironov, V.L.; De Roo, R.D.; Savin, I.V. Temperature-dependable microwave dielectric model for an Arctic soil. IEEE Trans. Geosci. Remote Sens. 2010, 48, 2544-2556. [CrossRef] 
40. Fang, X.; Pomeroy, J.W. Modelling blowing snow redistribution to prairie wetlands. Hydrol. Process. 2009, 23, 2557-2569. [CrossRef]

41. Li, L.; Pomeroy, J. Estimates of threshold wind speeds for snow transport using meteorological data. J. Appl. Meteorol. 1999, 36, 205-213. [CrossRef] 